\title{
O meio ambiente na mídia - um estudo de caso do jornal de maior circulação de Brasília.
}

\author{
Gabriela Xavier de Abreu' \\ Joana d'Arc Bicalho Félix²
}

\section{Resumo}

O meio ambiente é tema que vem ganhando importância mundial e isso se reflete na mídia. O presente trabalho apresenta uma pesquisa que verifica, por meio de um estudo de caso do jornal de maior circulação de Brasília e de alguns exemplares de outros importantes jornais e revistas, que de fato a frequência desse tema aumentou de 2000 a 2007. Além disso, observa-se que o meio ambiente permeia várias discussões na mídia impressa, porém nem sempre com a profundidade ou o direcionamento desejados. Por fim, destaca-se a influência que os profissionais do jornalismo têm na condução da notícia, inclusive no tocante às questões ambientais.

Palavras-chave: Meio ambiente. Mídia. Desenvolvimento sustentável. Comunicação para a Sustentabilidade

\footnotetext{
1 Autor - Orientanda: Gabriela Xavier de Abreu é Especialista em Análises Ambientais e Desenvolvimento Sustentável pelo UniCEUB. Graduada em Licenciatura e Bacharelado em Ciências Biológicas pela Universidade de Brasília.

2 Co-Autor colaborador - Orientadora: Joana d'Arc Bicalho Félix é formada em Comunicação Social, Doutoranda e Mestre em Planejamento e Gestão Ambiental com ênfase em Comunicação para a Sustentabilidade. Coordena a Pós-Graduação em Gestão da Comunicação nas Organizações, do UniCEUB. É multiplicadora do Instituto Ethos de Responsabilidade Social em decorrência do título Destaque-Regional Centro-Oeste com prêmio Ethos/Valor 2005. É jurada do Prêmio Ethos nacional, versão Pós-Graduação e versão Plano de Ensino. Professora de Pós-Graduação em Planejamento Estratégico, Comunicação, Gestão Ambiental, Marketing e Logística Reversa na UnB, UniCEUB e outras universidades. Foi jurada no Brasil do prêmio internacional Alcan Price for Sustainability, avaliando trabalhos sociais de Londres, Paquistão, Canadá, Bulgária e Brasil.
} 


\section{Introdução}

Desde que o devastador modelo de desenvolvimento capitalista foi adotado, os defensores do meio natural lutam para inserir a variável ambiental nas decisões políticas e econômicas, tanto internacionais quanto nacionais, por meio da tentativa de implementação de um modelo de desenvolvimento dito sustentável, ou ao menos, mais responsável social e ecologicamente. Vários avanços já foram conquistados na construção de uma base conceitual e institucional para o êxito desse novo modelo. No entanto, uma das premissas essenciais ao seu sucesso é a participação consciente da população mundial no processo de implantação, fazendo-se necessária uma mudança de paradigmas.

É nesse contexto que a educação ambiental adquire fundamental importância, sendo a mídia uma aliada em potencial e uma ferramenta essencial no processo de transformação. Com os avanços tecnológicos, resultando na globalização do processo informativo, os meios de comunicação de massa adquiriram uma presença marcante na vida das pessoas e, assim, um poder de influência notável sobre elas. Mas como esse poderoso instrumento está sendo usado e com que fins? Estaria ele formando cidadãos mais conscientes e responsáveis ambientalmente?

A hipótese que permeou este estudo é a de que os meios de comunicação estavam noticiando questões ambientais com maior frequência, acompanhando uma tendência mundial de crescimento do tema, porém de maneira ainda alarmista ou pontual e não trazendo uma visão sistêmica dos fatos. Para confirmar tal suposição, optou-se por trabalhar com um estudo de caso do jornal de maior circulação em Brasília, contextualizando essa análise com uma revisão de alguns exemplares dos principais jornais e revistas em circulação no Brasil.

No estudo, buscou-se verificar a frequência de aparição de notícias de cunho ambiental no período de 2000 a 2007, analisar o conteúdo de uma amostra dessas notícias e investigar a visão de um profissional do jornal estudado sobre o tema. Em relação aos outros jornais e revistas, o objetivo foi buscar uma visão mais geral e comparativa de como o tema estava sendo tratado. 


\section{Importantes veículos impressos de comunicação nacional}

A revista Veja é uma revista brasileira publicada semanalmente pela Editora Abril, uma das mais influentes da América Latina. Nos dias de hoje, possui uma tiragem superior a um milhão de exemplares, de acordo com o Instituto Verificador de Circulação - IVC (apud PlubiAbril) e constitui-se assim na revista de maior circulação no Brasil e a quarta maior revista semanal do mundo (PubliAbril; LUXNER, 2000). A revista IstoÉ também é uma revista semanal e atualmente é uma das revistas com maior circulação no país, e uma das dez maiores do mundo, possuindo uma tiragem média de 344 mil exemplares mensais, segundo o IVC (Editora Três; Máster em Jornalismo).

O jornal Folha de São - FSP é o jornal de maior circulação no país, com uma tiragem de mais de 360 mil exemplares aos domingos e 290 mil durante os dias da semana, de acordo com dados do IVC (PublicidadeFolha). O jornal é distribuído em todo o território nacional, todos os dias da semana. O jornal O Estado de São Paulo - ESP, também conhecido como Estadão, é distribuído em todo o território nacional, sendo o quarto maior em circulação, segundo dados do IVC, com uma média diária de cerca 250 mil exemplares (IVC, 2007). O O Globo - OG é um jornal impresso diário, de distribuição nacional. É o terceiro maior jornal impresso em circulação no país, com distribuição de mais de 270 mil exemplares diários nos dias de semana e mais de 374 mil aos domingos, perfazendo assim uma média de mais de 285 mil exemplares diários, no mês de janeiro de 2008 (IVC apud InfoGlobo). Por fim, o Jornal do Brasil - JB é um diário nacional que ocupa o $13^{\circ}$ lugar no ranking de circulação da IVC (IVC, 2007), e possui uma média de 98 mil exemplares diários.

O jornal Correio Braziliense, estudo de caso na presente pesquisa, pertence hoje ao complexo empresarial Grupos Associados. O jornal foi fundado em 21 de abril de 1960, pelo então Diários dos Associados, nascendo de um desafio assumido por Francisco de Assis Chateaubriand de lançar um jornal que acompanhasse a nova capital desde seus primórdios. Atualmente, é considerado como o mais importante jornal de Brasília, ocupando a $21^{a}$ posição no ranking nacional de participação e evolução das publicações, do Instituto Verificador de Circulação (IVC, 2007), relativo aos diários pagos ativos em todo o Brasil em outubro de 2007. Ainda, segundo este ranking, no período analisado, ele possuía uma participação 
de $1,31 \%$ no mercado nacional e mantinha uma média de publicação de 54.746 exemplares diários.

\section{0 meio ambiente na mídia pesquisada}

A observação acerca da temática ambiental foi realizada por meio da leitura das edições de 17 de dezembro de 2007 do jornal O Globo - OG, de 18 de dezembro de 2007 dos jornais Jornal do Brasil - JB e Folha de São Paulo - FSP e da edição de 12 de fevereiro de 2008 do jornal Estado de São Paulo - ESP, além das edições de 19 de dezembro de 2007 das revistas Veja e IstoÉ. Foram consideradas todas as seções das edições citadas, excluindo-se, no entanto, as páginas de Classificados dos jornais, por se considerar que essas não trariam informações relevantes para a análise.

Por meio da leitura do material, identificaram-se as matérias que abordavam explicitamente a temática ambiental, seja de forma pontual ou profundamente, incluindo-se os anúncios publicitários. As matérias selecionadas dessa maneira foram resumidas e listadas. Considerou-se como "matéria” qualquer tipo de reportagem, nota, coluna, artigo, quadro explicativo, chamada de reportagem, editorial, carta, ou legenda, distinguindo essa categoria da de "publicidade".

Na tabela 1, percebe-se que, nas duas revistas analisadas, o número de referências ao meio ambiente encontradas em publicidades é muito alto, se comparado ao número total de menções ao tema nesses veículos. Em relação ao número de páginas onde o meio ambiente é citado, nota-se que as correspondentes a anúncios publicitários superam aquelas dedicadas a matérias na revista Veja e correspondem a $35 \%$ na IstoÉ.

Não há ou consta de forma irregular a presença de seção específica para o meio ambiente. Em compensação, vale ressaltar que, em todos os jornais e revistas analisados, havia uma seção Economia ou Dinheiro. 


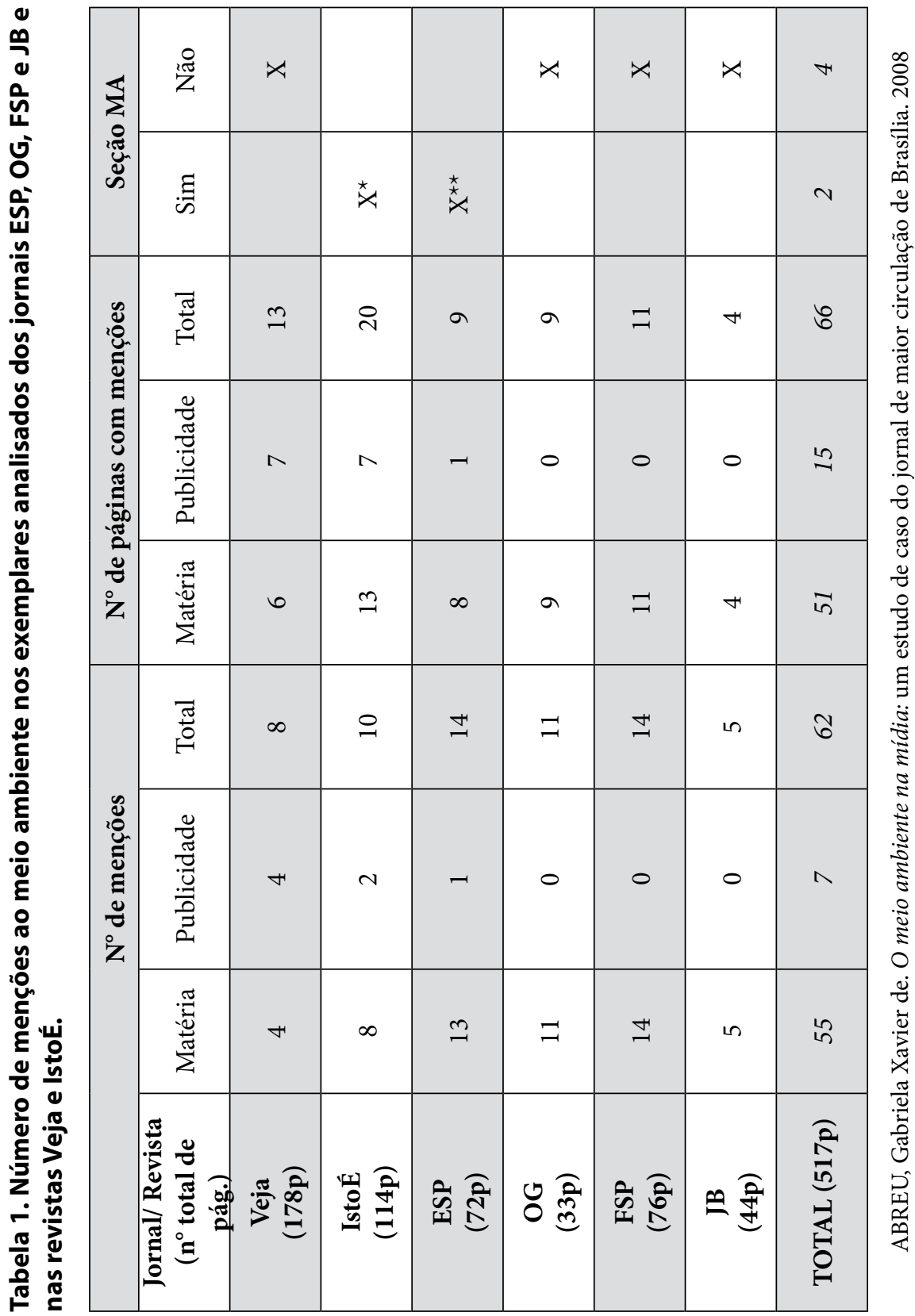




\section{A abordagem do tema na mídia}

Ao se focar no conteúdo das matérias analisadas, nota-se que o meio ambiente, na maioria das vezes, é apenas citado, não sendo um fator decisivo na reflexão ou nas informações trazidas pelo texto. Na revista Veja, a única matéria que de fato discute uma questão ambiental trata de um novo tipo de lâmpadas elétricas que estava sendo usado nas árvores de Natal dos Estados Unidos da América (EUA), frisando principalmente a tecnologia envolvida e seus benefícios, como a economia de energia. A matéria, intitulada $A$ evolução da luz: as lâmpadas LED já substituem com grandes vantagens a velha invenção de Thomas Edison, é finalizada com a frase "As lâmpadas LED são a prova de que o desenvolvimento tecnológico é a forma mais eficiente de combater o aquecimento global" (CORREA, 2007, p.119).

Na revista IstoÉ, é interessante notar que há duas matérias que poderiam abordar a questão ambiental de forma mais profunda e sistêmica, pois tratam do consumismo de fim de ano e das hidrelétricas do rio Madeira, respectivamente; porém, não o fazem. A primeira, intitulada Frenesi do consumo (JORDÃO, 2007), apenas menciona o grande sucesso de vendas de sacolas ecológicas, entretanto sem abordar a finalidade para as quais elas foram criadas; e a segunda, de título $A$ batalha do rio Madeira (STUDART, 2007), apesar de trazer foto de manifestantes de movimentos socioambientais, apenas cita seus protestos em uma frase e foca toda a discussão sobre as disputas empresariais e econômicas do processo licitatório do empreendimento.

Por fim, em relação a essas duas revistas, vale sublinhar que ambas traziam uma reportagem sobre a greve de fome do bispo Luiz Cappio contra a transposição do rio São Francisco, no entanto, nenhuma das duas abria discussão sobre a transposição e sim sobre a personagem do bispo. A matéria da Veja intitulava-se O pecado do franciscano (PORTELA, 2007) e a da IstoÉ, A loucura de um bispo (RODRIGUES, 2007)

Os jornais, de uma forma geral, traziam matérias com reflexões mais profundas que integravam fatores ambientais, econômicos, legais, políticos e sociais, principalmente quando se tratavam de editoriais. É o caso, por exemplo, dos artigos Desfile do campo (GRAZIANO, 2008) e Mercado agrícola em transformação (BARBOSA, 2008) sobre o setor agrícola, presentes no ESP, ou da reportagem Por 
um comércio mais justo (BECK, 2007) sobre uma iniciativa de "comércio justo" no OG, que trazia informações sobre uma alternativa econômica, social e ecologicamente viável de empreendimento. No entanto, os jornais também traziam matérias que abordavam o tema do meio ambiente de forma mais superficial ou pontual.

O tema mais recorrente em todos os veículos analisados foi a $13^{\text {a }}$ Conferência da Convenção de Mudanças Climáticas das Nações Unidas. O que chama a atenção ao comparar quatro matérias é a diversidade de enfoque com destaque a alguns dos textos que se limitam a uma análise das disputas políticas e medição de forças entre os países participantes da Conferência.

\section{Frequência de informações socioambientais na mídia}

A utilização da ferramenta de busca de notícias do jornal estudado permitiu a realização dos seguintes gráficos para avaliação da frequência de matérias com temas ambientais no período de 2000 a 2007.

Figura 1. Gráfico de frequências absolutas de aparição dos termos "desenvolvimento sustentável", "responsabilidade social", "aquecimento global" e"meio ambiente" por ano, no período de 2000 a 2007.

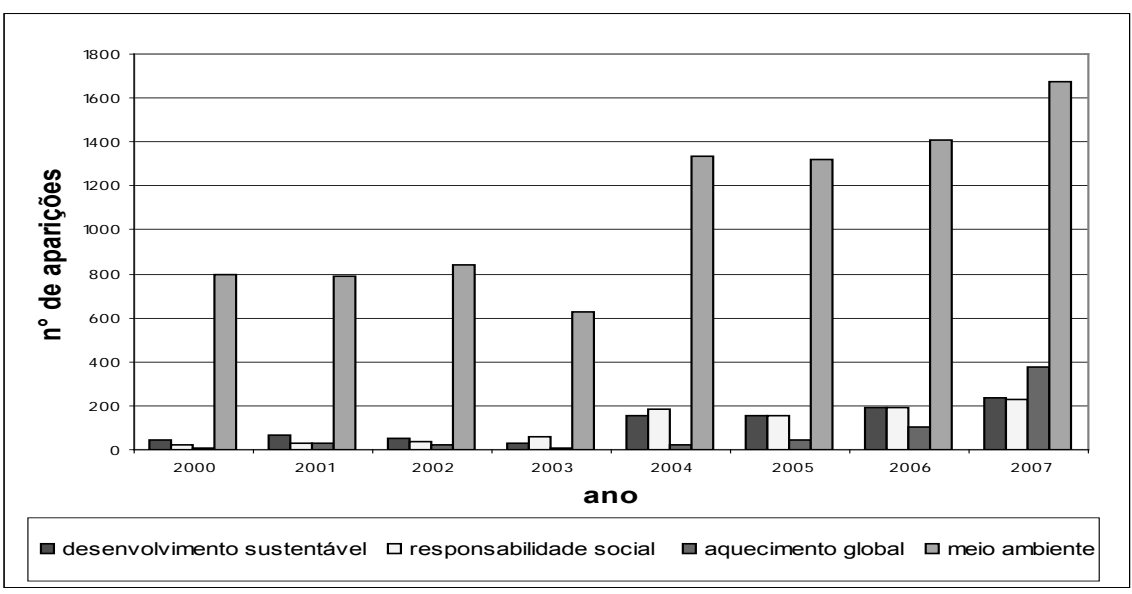

ABREU, Gabriela Xavier de. O meio ambiente na mídia: um estudo de caso relacionado jornal de maior circulação de Brasília. 2008. 
No gráfico, fica clara uma tendência de forte crescimento nas frequências absolutas de aparição de todos os termos pesquisados, havendo apenas uma diminuição geral no ano de 2003. Pode se também notar que o termo "meio ambiente" aparece em número muito superior aos outros e que a sua frequência absoluta mais do que dobra de 2000 a 2007.

Além das frequências absolutas dos termos mencionados, pesquisou-se também a frequência relativa do termo "meio ambiente" no mesmo período. Os resultados são apresentados no gráfico da figura 2 .

Figura 2. Porcentagem de aparições do termo "meio ambiente" em relação ao total de matérias por ano.

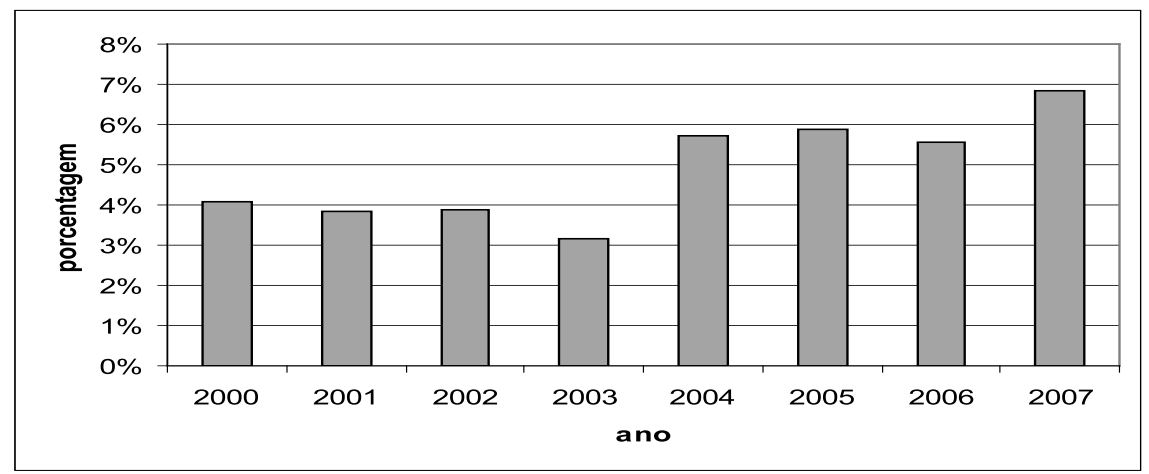

ABREU, Gabriela Xavier de. O meio ambiente na mídia: um estudo de caso do jornal de maior circulação de Brasília. 2008

O gráfico da figura 2 demonstra uma tendência de crescimento da porcentagem de aparições do termo "meio ambiente" em relação ao total de matérias. No entanto, percebe-se que o aumento constatado nas porcentagens de aparições do termo "meio ambiente" não tem a mesma amplitude do que o aumento da frequência absoluta desse mesmo termo.

Ainda com o objetivo de analisar a importância numérica de matérias que abordam a temática ambiental, realizou-se uma busca da frequência absoluta de aparições do termo "meio ambiente" por ano em comparação com a frequência absoluta de aparições do termo "economia”. Dessa forma, buscou-se obter um parâmetro de comparação dessa frequência. 
Nos anos de 2000 a 2003, o valor da frequência absoluta do termo "economia" é cerca de quatro vezes superior ao valor da frequência absoluta do termo "meio ambiente"; já em 2004, essa proporção diminui até o valor da frequência absoluta do termo "economia" ser menos de 2,5 vezes maior do que o valor da frequência absoluta do termo "meio ambiente" em 2007.

Figura 3. Frequência absoluta de aparições dos termos "meio ambiente" e "economia" por ano, de 2000 a 2007.

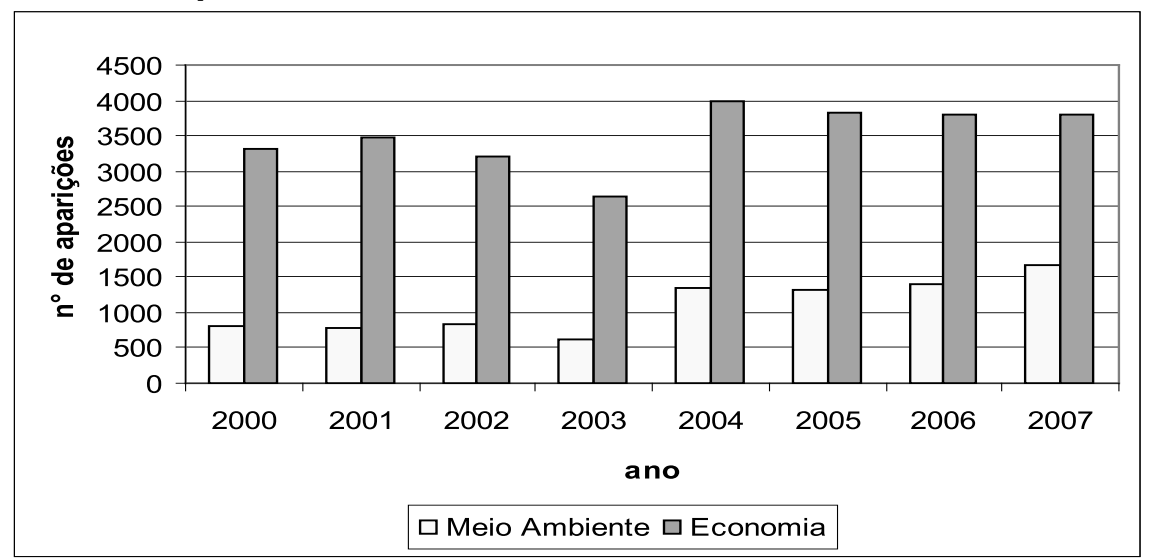

ABREU, Gabriela Xavier de. O meio ambiente na mídia: um estudo de caso do jornal de maior circulação de Brasília. 2008

\section{Como o conteúdo socioambiental é abordado no jornal}

Nessa fase da pesquisa, foram selecionadas e analisadas 53 matérias, contendo o termo "meio ambiente" no ano de 2007. Assim foi possível classificá-las em nove categorias temáticas como mostra a figura 4 .

Ao analisar-se o gráfico da figura 4, pode-se ver que a categoria temática de maior importância foi a de Espaço urbano (notícias relativas ao crescimento urbano e ocupação do espaço público), abarcando 22,6\% das matérias analisadas, seguida pela de Crime ambiental (notícias denunciando ações em desacordo com as normas ambientais), com 17\% e pela de Anúncio (avisos públicos obrigatórios por lei ou anúncio de vagas na área ambiental), com 13,2\%. Todas as outras categorias reúnem menos de $10 \%$ das matérias cada uma, sendo a menos importante 
Figura 4. Quantidade relativa de matérias por categoria temática.

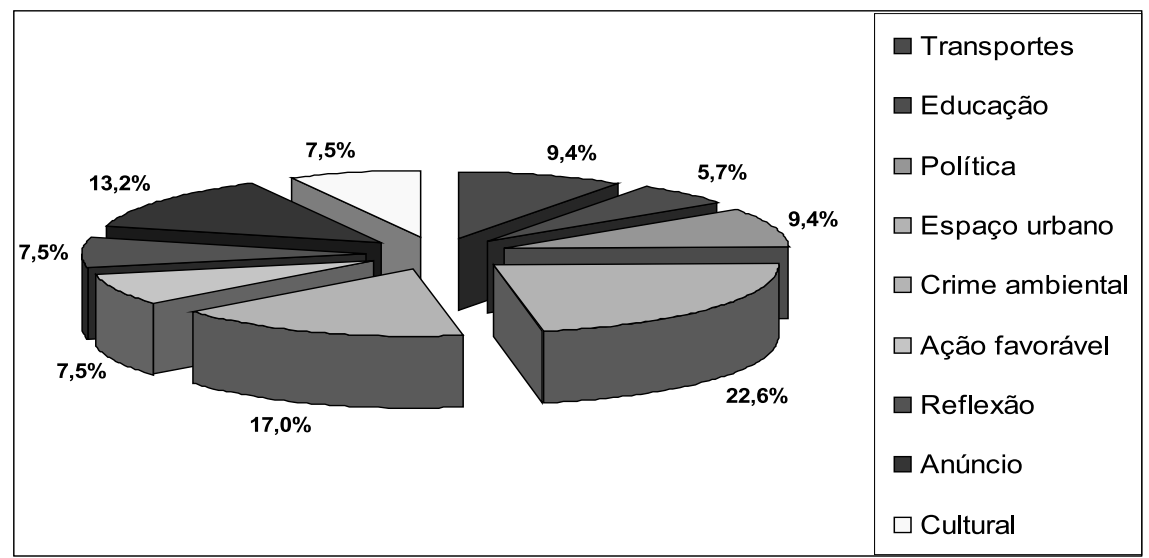

ABREU, Gabriela Xavier de. O meio ambiente na mídia: um estudo de caso do jornal de maior circulação de Brasília. 2008

a de Educação (notícias de projetos educacionais ou matérias sobre o conteúdo de cursos). Destaca-se também a pouca representatividade da categoria Ação favorável (matérias sobre iniciativas em favor do meio ambiente), com apenas 7,5\%.

\section{Discussão dos resultados}

Por meio da presente pesquisa, pode-se perceber que há vários indícios de que o meio ambiente está sendo mais discutido tanto nos meios de comunicação, quanto na sociedade de forma geral, acompanhando, portanto, uma tendência histórica mundial de crescimento na importância desse tema.

De fato, no estudo de caso, observou-se que, de maneira geral, a frequência absoluta de matérias contendo termos ligados ao meio ambiente aumentou substancialmente nos últimos sete anos (figura 1). Também corrobora esse crescimento o aumento na proporção de matérias, contendo o termo "meio ambiente" em relação ao número total de matérias publicadas, como observado no gráfico da figura 2. Além disso, verificou-se uma diminuição na diferença entre a frequência absoluta de matérias, contendo o termo "meio ambiente" e a de matérias com o termo "economia" ao longo dos anos, apesar de o uso desse último termo ainda ser muito mais alto. 
Outro indício de uma abordagem mais frequente de aspectos ambientais pela mídia é a verificação de que esse tema está permeando vários tipos de discussões, como foi mostrado na classificação das notícias por categorias temáticas (figura 4) do estudo de caso. Entretanto, se o meio ambiente está cada vez mais presente nas pautas jornalísticas e dentre as preocupações da sociedade, cabe questionar de que maneira essa discussão é levada adiante. Analisando a questão, vem à tona o caráter alarmista de muitas das publicações. Além da opinião do jornalista entrevistado, a grande proporção de matérias classificadas dentro da categoria temática Crime ambiental também aponta para uma quantidade importante dessas matérias denunciativas. Por outro lado, a pequena proporção de matérias na categoria temática Ações favoráveis pode sugerir duas explicações: ou há menos ações benéficas ao meio ambiente do que crimes e danos contra este, ou esses últimos estão sendo mais noticiados do que os primeiros.

Em relação ao comportamento de algumas mídias impressas brasileiras especificamente sobre a abordagem de temas ambientais, podem-se destacar algumas evidências. No estudo da mídia em geral, no tocante ao meio ambiente, constata-se que as revistas avaliadas continham uma quantidade muito maior de publicidades do que os jornais, chegando ao extremo de esse tipo de material ocupar 50\% do conteúdo selecionado na revista Veja e 35\% das páginas selecionadas na revista IstoÉ. Esses dados sugerem que as revistas, provavelmente por terem um objetivo maior de entretenimento em relação aos jornais, estão mais associadas à indústria cultural conceituada por Adorno e Horkheimer (apud COSTA, 2001) e, portanto, usam do tema meio ambiente como um bem mercadológico.

Essa associação com a indústria cultural também fica evidente em matérias que não se encaixam no material publicitário, como é o caso da matéria sobre consumismo publicada no exemplar analisado da revista $I s t o E$. Na referida reportagem, toca-se em um tema crucial na discussão de um desenvolvimento mais responsável ecologicamente, a saber, a criação constante de novas necessidades (MENDES, 1993; VARGAS, 2005), principalmente de ordem material, significando maior produção industrial e, portanto, maior utilização de recursos naturais e produção de resíduos. No entanto, a ótica privilegiada pelo autor não é a da não-sustentabilidade de um modelo baseado no consumo crescente de bens materiais, nem tampouco as implicações positivas que um artigo dito ecológico traz consigo, e sim apenas o seu sucesso de vendas. 
Um dos fatos que se pode sublinhar é que não existem seções específicas para o meio ambiente. Em compensação, todos os veículos citados apresentam uma seção fixa intitulada Economia ou Dinheiro. Obviamente, pela questão ambiental ser multidisciplinar por natureza (MENDES, 1993), poder-se-ia argumentar que não faria sentido engessá-la em uma única seção. No entanto, deve-se considerar que a existência de uma seção fixa para o meio ambiente, assim como há para a economia, não impede que esse tema seja abordado também em outras partes do veículo de comunicação, ou mesmo com temáticas transversais. A presença dessa seção somente representaria um compromisso em se tratar do tema com maior regularidade, viabilizando abordagens que apuram várias faces de um mesmo fato, bem como transmitem conhecimentos e informações que formam e educam o leitor.

Ainda a favor da argumentação de que os fatores econômicos pesam mais do que os ambientais, está o fato da frequência absoluta do termo "economia" no jornal de maior circulação de Brasília continuar aproximadamente 2,5 vezes superior à frequência absoluta do termo "meio ambiente" no ano de 2007.

Apesar dessa constatação, algumas das matérias analisadas são representativas do pensamento de que é possível aliar fatores econômicos com preocupações ambientais apontando, portanto, para a existência de alternativas condizentes com o desenvolvimento sustentável. É o caso, por exemplo, da matéria publicada na seção de Economia do exemplar analisado do jornal $O G$ sobre comércio justo. Essa reportagem trata da comercialização de artigos produzidos de forma ecológica e socialmente responsável e as possibilidades financeiras desse comércio, apresentando modos positivos de buscar um desenvolvimento menos injusto socialmente e menos danoso ambientalmente.

Outra questão que vale comentar é a da subjetividade do jornalista em relação à informação que está sendo trazida por ele (FLAUSINO, 2001). Na análise feita com as revistas e os jornais impressos, dois exemplos chamam atenção nesse sentido. $\mathrm{O}$ primeiro exemplo refere-se às matérias sobre a greve de fome do bispo Luiz Cappio contra a transposição do rio São Francisco, publicadas na Veja e na IstoÉ. De fato, a IstoÉ apenas cita a discussão ecológica da transposição, e a Veja nem sequer menciona os aspectos socioambientais envolvidos. Fica claro, portanto, como os responsáveis pela notícia podem focar a discussão em determinado 
aspecto e optar por discutir ou não aspectos mais relevantes do ponto de vista ambiental. $\mathrm{O}$ segundo exemplo é o das matérias relativas à conferência sobre mudanças climáticas em Bali, publicadas na revista IstoÉ e nos jornais FSP e JB. Ao se deter sobre essas matérias, nota-se que elas abordam o tema sob pontos de vistas diversos, chegando algumas a se deterem apenas na atuação dos representantes durante a reunião, não abordando o que está sendo discutido. Vê-se, portanto, que a forma como um tema pode ser transmitido depende muito de como o autor se coloca e a qual assunto ele escolhe dar ênfase.

Nesse contexto, uma das peças jornalísticas analisadas chama a atenção justamente em relação às ideias que são defendidas em seu conteúdo. A matéria em questão é a que apresenta os novos tipos de lâmpadas elétricas das árvores de Natal americanas, publicada na revista Veja. Nessa reportagem, a argumentação é direcionada no sentido de afirmar que os avanços tecnológicos representam a melhor solução para o enfrentamento dos problemas advindos do aquecimento global.

Essa ideia é muito difundida e tem apoio, inclusive, no relatório Nosso Futuro Comum da Comissão Brundtland (CMMAD, 1991). No entanto, diante da reflexão defendida por tantos autores (MENDES, 1993; BURSZTYN, 2001; DOWBOR, 2004; MORAIS, 2004; VARGAS, 2005) e no presente estudo, de que é necessária uma mudança de valores e hábitos para caminhar em direção a um desenvolvimento mais responsável social e ambientalmente, essa argumentação direcionada se torna um tanto quanto perigosa. É evidente que os avanços tecnológicos, principalmente em relação ao uso de recursos naturais não-renováveis, são fundamentais no processo de diminuição dos impactos negativos gerados ao meio natural. Entretanto, esse fato não deve ser colocado como única forma de se alcançar um desenvolvimento menos agressivo ecologicamente, mascarando assim a necessidade de esforços em outras frentes, como por exemplo, na redução de consumo de bens e energia. Aliás, haja vista a complexidade da questão ambiental que envolve tanto aspectos sociais quanto econômicos, educacionais, ecológicos e outros, qualquer solução apontada como única parece bastante suspeita e por demais simplista.

Assim sendo, a supracitada matéria da Veja mostra que, apesar de uma preocupação cada vez maior com o meio ambiente, inclusive dentre os jornalistas, nem sempre a questão é abordada com a profundidade de análise desejada. Mais 
do que isso, essa reportagem dividia o espaço que lhe foi reservado na revista com uma propaganda da companhia energética Furnas sobre a construção da hidrelétrica do rio Madeira.

Diante dos exemplos analisados, fica evidente que o jornalista, por suas escolhas e ideias, tem um papel fundamental na condução da notícia e, mais ainda, na influência que a mesma terá sobre o leitor. Quando o profissional escolhe tratar apenas aspectos pontuais ou isolados de determinado tema, como a intriga diplomática durante uma conferência de mudanças climáticas, ou o número de dias em que uma sacola ecológica esgotou no mercado, ele está deixando de mencionar aspectos mais relevantes a um melhor entendimento da sociedade e de seus processos, fator imprescindível para o desenvolvimento sustentável. O mesmo ocorre com uma análise em que apenas uma das faces de um problema extremamente complexo, como o da questão energética, é apresentada, numa tentativa de simplificação que acaba sendo tendenciosa. Com isso, a notícia deixa de contribuir para a conscientização dos leitores, abordando questões que, de fato, falam de meio ambiente, porém, não trazem informações relevantes a uma possível mudança de perspectiva e, portanto, de atitude em relação a ele.

\section{Conclusão e Recomendações}

Os dados apresentados mostraram que o meio ambiente está sendo abordado pela mídia com maior frequência e no âmbito das mais diversas discussões. Entretanto, também foi possível verificar que muitas matérias que tratam do tema ainda o fazem em um tom denuncista ou alarmista, não havendo necessariamente uma continuidade dos assuntos expostos, o que corrobora a hipótese do presente estudo.

Além disso, percebeu-se que a profundidade das análises emitidas na mídia acerca da temática ambiental varia muito e tem uma relação estreita com a subjetividade da informação jornalística. De fato, a seriedade e o direcionamento das informações oferecidas pelos jornais e revistas estão fortemente atrelados à visão e à amplitude da consciência ambiental dos jornalistas. 
Diante disso, cabe questionar a falta de um comprometimento explícito dos veículos de comunicação e de seus profissionais em divulgar dados de qualidade e reflexões mais abrangentes no tocante ao meio ambiente. A importância que a mídia pode ter na sensibilização da população diante do desafio de adoção de um modelo de desenvolvimento mais responsável social e ambientalmente deve ser reconhecida e assumida.

Assim sendo, sugere-se a realização de estudos para investigar o grau de entendimento que os jornalistas têm das questões envolvendo o meio ambiente, buscando correlacioná-lo com a formação que esses profissionais recebem e as possíveis pressões que eles sofrem nas redações.

\section{Abstract}

The environment is a growing subject worldwide and this reflects in media. The following work presents a research that assesses, through a case study of the most important newspaper of Brasília and some editions of other important newspapers and magazines, that, in fact, the frequency of this subject has grown from 2000 to 2007. In addition, it observes that the environment integrates many discussions in printed media, but not always with the desired profundity or direction. At last, the influence journalists have in conducting news is noticed, also regarding environmental issues.

Keywords: Environment. Media. Sustainable development. Communication for sustainability.

\section{Referências}

BARBOSA, Rubens. Mercado agrícola em transformação. O Estado de São Paulo. n. 41755, ano 129, 12 fev 2008. p. A2. Disponível em: <http://www.estado.com. br/editorias/2008/02/12/opi-1.93.29.20080212.3.1.xml>. Acesso em: 24 nov. 2008.

BECK, Martha. Por um comércio mais justo: em alta no mundo, venda de produtos com preocupação ecológica e social será incentivada no país. O Globo, [S.l], n. 27160, ano LXXXIII, p.17, dez. 2007. 
BURSZTYN, Marcel. Políticas públicas para o desenvolvimento (sustentável). In: BURSZTYN, Marcel (Org.) A difícil sustentabilidade: políticas energéticas e conflitos ambientais. Rio de Janeiro: Garamound. 2001. p. 59-76.

CMMAD. Nosso futuro comum. Rio de Janeiro: Fundação Getúlio Vargas. 1991.

CORREA, Rafael. A evolução da luz: as lâmpadas LED já substituem com grandes vantagens a velha invenção de Thomas Edison. São Paulo, v. 2039, n. 50, ano 40, p. 118-119, dez. 2007.

COSTA, Belarmino Cesar Guimarães da. Barbárie estética e produção jornalística: a atualidade do conceito de indústria cultural. Educação \& Sociedade. [S.1], n. 76, ano XXII, p. 106-120, out. 2001.

DOWBOR, Ladislau. Informação para a cidadania e a sustentabilidade. 2004. 16 p. Disponível em:<http://dowbor.org/04infocid.doc >. Acesso em: 29 nov. 2007.

EDITORA Três. Disponível em:<http://editora3.terra.com.br/index.htm $>$. Acesso em: 26 mar. 2008.

FLAUSINO, Márcia Coelho. Notícia: conduzindo a compreensão da realidade - cotidiano, imaginário e representações sociais. In: BARROS, Antonio; DUARTE, Jorge; MARTINEZ, Regina (Orgs). Comunicação: discursos, práticas e tendências. São Paulo: Rideel; Brasília: UniCEUB, 2001, p. 103-118.

GRAZIANO, Xico. Desfile do campo. O Estado de São Paulo. n. 41755, ano 129, 12 fev 2008. p. A2. Disponível em: < http://www.estado.com.br/ editorias/2008/02/12/opi-1. 93.29.20080212.1.1.xml>. Acesso em: 24 nov. 2008.

INFOGLOBO. Disponível em: <http://www.infoglobo.com.br/mercado_ circulacaoivc.asp\#>. Acesso em: 26 mar. 2008.

INSTITUTO Verificador de Circulação, IVC. Posição participação e evolução das publicações. Disponível em: <http://www.redetribuna.com.br/images/ ranking.pdf $>$. Acesso em: 18 mar. 2008.

JORDÃO, Claudia. Frenesi do consumo. IstoÉ, v. 1990, ano 30, 19 dez. 2007. p. 68-71. Disponível em: <http://www.terra.com.br/istoe/edicoes/1990/ artigo68710-1.htm>. Acesso em: 24 nov. 2008. 
LUXNER, Larry. Bridging the digital divide: Brazil's Grupo Abril. 2000. Disponível em: <http://www.luxner.com/cgi-bin/view_article.cgi? articleID=42>. Acesso em: 26 mar. 2008.

MÁSTER em jornalismo. Notícias. IVC aponta aumento na circulação de revistas populares. Disponível em: <http://www.masteremjornalismo.org.br/noticia_view. php?id=1432>. Acesso em: 26 mar. 2008.

MENDES, Armando Dias. Breve itinerário dos ecossistemas à ecopoesia: achegas para o seu traçado. In: BURSZTYN, Marcel (Org). Para pensar o desenvolvimento sustentável. IBAMA/ENAP. São Paulo: Brasiliense, 1993. p 11-27.

MORAIS, Regis de. Educação, mídia e meio ambiente. Campinas: Alínea, 2004.

PORTELA, Fábio. O pecado do franciscano. São Paulo, v. 2039, n. 50, ano 40, 19 dez. 2007. p. 138. Disponível em: <http://veja.abril.com.br/191207/p_138.shtml>. Acesso em: 24 nov. 2008.

PUBLIABRIL. Editora Abril. Disponível em: <http://www.abril.com.br/br/home/>. Acesso em: 26 mar. 2008.

PUBLICIDADEFOLHA. Folha de São Paulo. Circulação. Perfil do Leitor. Disponível em: <http://publicidade.folha.com.br/>. Acesso em: 26 mar. 2008.

RODRIGUES, Alan. A loucura de um bispo. IstoÉ, v. 1990, ano 30, 19 dez. 2007. p. 29-30. Disponível em: <http://www.terra.com.br/istoe/edicoes/1990/ artigo68743-1.htm > Acesso em: 24 nov. 2008.

STUDART, Hugo. A batalha do rio Madeira. IstoÉ, v. 1990, ano 30, 19 dez. 2007. p. 92-93. Disponível em: <http://www.terra.com.br/istoe/edicoes/1990/ artigo68742-1.htm>. Acesso em: 24 dez. 2008.

VARGAS, Everton Vieira. A sustentabilidade como valor. In: BATISTA, Eleizer; CAVALCANTI, Roberto B.; FUJIHARA, Marco Antônio. Os caminhos da sustentabilidade no Brasil. São Paulo: Terra das Artes. 2005. p. 34-42. 